\title{
GC-MS/MS Analysis of Benzo(a)pyrene by Ion Trap Tandem Mass Spectrometry
}

\author{
Jae Jak Nam and Sang Hak Lee ${ }^{\dagger}$

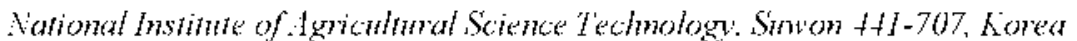

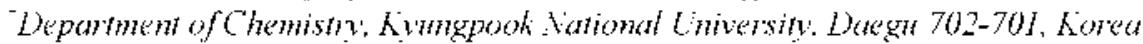 \\ Received Harch 29, 2002
}

\begin{abstract}
The mass spectrometry using an ion trap tandem mass spectrometer has been investigated to find optinum conditions for the analy sis of benzo(a)pyene (3,4-benzpyene). The applicability to a real soil sample was also investigated to verify the usefulness of the MS/MS (or collision induced dissociation, (CID) analysis. 'lhe optinum CID condition was 1.5 and 0.45 for the $R F$ excitation voltage and the q value, respectively. For comparison, (ID) and El were applied to the analysis of a soil sample. ('ID analysis was more sensitive than $E I$ analysis of the soil sample. The limit of detection (LOD) of benzo(a)pyrene was $3.18 \mathrm{ng} \mathrm{mL}{ }^{1}$ and $0.85 \mathrm{ng}$ $\mathrm{mL}{ }^{\mathrm{i}}$ for $\mathrm{El}$ and $\mathrm{MS} / \mathrm{MS}$ analy sis. respectively. The precision at the soil sample for $\mathrm{El}$ and (II) showed relative standard deviations of $6.1 \%$ and $4.1 \%$, respectively, and the concentrations were $168 \mu \mathrm{g} \mathrm{kg}{ }^{1}$ and $162 \mu \mathrm{g}$ kg ', respectively.
\end{abstract}

Key words: PAHs, Benro(a)py rene, Ion trap mass spectronetry, CID, MS/MS

\section{Introduction}

Benzo(a)pyrene is a compound of polycyclic aromatic lydrocarbons (PAHs). PAHs. products of combustion involving carbonaceous fuels, are found in grilled meat, ${ }^{1}$ tobacco smoke. airborne particles. ${ }^{2}$ used motor oil. ${ }^{3}$ soils, $^{4}$ and are formed in practically all processes involving combustion of fossil fuels. Among the parent PAHs, benzo(a)py rene is the most toxic and carcinogenic. ${ }^{i}$ Benzo(a)pyrene is quite widespread in the enviromment since it is an ubiquitous product of incomplete combustion. It is largely associated with particulate matter, soils, and sediments. Although environmental concentrations are highest near sources, benzo(a)pyrenes presence in places distinct from primary sources indicates that it is reasonably stable in the atmosphere and capable of long-distance transport. "The global emission of benzo(a)pyrene derived from exogenous sources has been estimated at about 5.000 tons per year. a quantity that appears to exceed that formed endogenically: Therefore, the monitoring of PAHs in the environment is of considerable importance.

The main problem with the determination of PAHs is the complexity of environmental matrices and the presence along with the PAHs of many interfering substances that camnot be removed by repeated extraction and purification." Current analytical methods for the analysis of benzo(a)pyrene, including PAHs in various matrices, generally use liquid chromatographic (LC) or gas chromatographic (GC) separation. Most PAH methods have been commonly used historically for routine monitoring, including $\mathrm{PAH}$ parent compound standard method. The methods include EPA (Environmental Protection Agency) Methods 550.610.625. $8100,8250.8270$. and $8310^{9.11}$ All methods involve a preconcentration or cleanup step before sample separation. Detection is by flame ionization detector fluorescence detector, ultraviolet detector. or mass spectrometry. Note that these methods are sometimes inadequate for generating scientifically defensible information. ${ }^{11}$ When biological effects, ecological risk assessment, damage assessment. or bio-remediation are being considered. the detection limit should be no higher than $\mathrm{l}-10 \mathrm{ng} \mathrm{\textrm {L } ^ { - 1 }}$ for water and $1 \mu \mathrm{g} \mathrm{kg}^{-1}$ dry weight for solids such as tissues, sediments, and soil.

The ion trap mass analyzer is an assembly composed of an entrance endcap electrode. central ring electrode, and exit endcap electrode. When the proper RF voltage is applied to the central ring electrode relative to both endcap electrodes. a three-dimensional rotationally symmetric quadrupole electric field is created. lons of selected mass-to-charge ratios can be stored in this field in stable orbits. As the RF voltage is increased, the trapped ions become unstable in order of increasing mass-to-charge ratio. Ions with unstable orbits are ejected from the ion trap mass analyzer and are then passed on to the ion detection system. '? The ion trap mass spectrometer can identify analytes at the picogram level in the full scan mode. As a high sensitivity detector, the ion trap mass spectrometer has the potential to eliminate or reduce sample preparation steps. In addition. ion trap detectors can perform tandem mass spectrometry (MS/ MS). ${ }^{1.3}$ This capability enables the ion trap to isolate an ion of interest and then produce characteristic progeny ions by collision induced dissociation (CID) and to distinguish unambiguously the compounds from other compounds that have parent ions of the same mass-to-charge ratio.

Previous CL (or MS/MS) experimentation on the ion trap mass spectrometer has been performed. for example. on hydroxylated polychlorinated bipheny.ls. ${ }^{1+}$ nonylphenol polythoxylates and their degradation products. 15 and polyaromatic quinones. ${ }^{16}$ Also. the application of ion trap tandem mass spectrometry for PAHs analysis was conducted in 1997.3 For several years the instrumentation of ion trap mass spectrometry was remarkably progressive, and the sensitivity and repeatability improved noticeably 
The objective of the present paper is to find an adequate parameter of the MS/MS method for quantitative determination of benzo(a)pyrene with the most sensitive and the lighest $\mathrm{S} / \mathrm{N}$ ratio. The method should. along with other methods, assess the limit of detection (LOD) and standard deviation of replications. The second part of this work presents an application of the CID experiments to real samples and describes the determination of benzo(a)pyrene in soil sample.

\section{Experimental Section}

Chemicals. Pesticide residue analysis grade dichloromethane, pentane, isooctane, and cyclohexane were obtained from Fisher Scientific (Pittsburgh PA. USA) and analytical grade silica gel and sodium sulfate were obtained from Merck (Darmstadt. Germany). Bellzo(a)py rene (Figure 1) standard and intemal standard were obtained from AccuStandard (USA). Perylene- $d_{1}=$ was used as an intemal standard for the quantitation of benzo(a)py rene.

Sample preparation. A soil sample was collected in the confronted iron processing plant in Kwang-Yang city: The soil samples were extracted for 16 hours with dichloromethane (20 g soil. $200 \mathrm{~mL}$ extractant) in Soxhlet apparatus. Before extraction. an internal standard was spiked to the soil. Silica gel column clean up was used for purification of the extract. according to EPA method $3630 .{ }^{9}$ The eluant from column was evaporated to about $1 \mathrm{ml}$ before andysis.

Instrumentation. A PolarisQ. including TraceGC 2000 (ThermoFinnigan Corp., Austin. TX. USA) integrated GCMS/MS system (ion trap with external ionization) fitted with the ligh temperature ion source was used. The system was controlled from a PC with the Xcalibur 1.2 software (ThermoFinnigan Corp.).

Gas chromatography. A ThermoFinnigan AS 2000 autosampler was used to inject samples $(1.0 \mu \mathrm{L})$ in splitless mode at $285^{\circ} \mathrm{C}$ (split after 1 minute. $30 \mathrm{~mL} \mathrm{~min}^{-1}$ ) in a 5 mm ID Focusliner (Restek. USA). Separation was performed on a $30 \mathrm{~m} \times 0.25 \mathrm{~mm}$ (ID) $0.25 \mu \mathrm{m}$ film thickness, Rtx-5 ms fused-silica column (Restek. USA). The oven temperature program started at $75^{\circ} \mathrm{C}$. held for $5 \mathrm{~min}$. and increased to $150^{\circ} \mathrm{C} \mathrm{C}$ at a rate of $25^{\circ} \mathrm{C} \mathrm{min}^{-1}$. and then to $265^{\circ} \mathrm{C}$ at a rate of $4^{\circ} \mathrm{C} \mathrm{min}^{-1}$. The final temperature was held for $10 \mathrm{~min}$ and

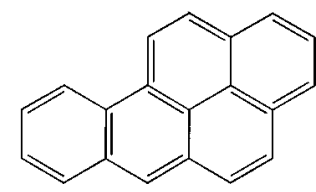

Figure 1. Structute of beslog(a)pyrente increased to $285^{\circ} \mathrm{C}$ at $30^{\circ} \mathrm{C} \mathrm{min}^{-1}$. Pressure programming gave a constant linear gas velocity of $40 \mathrm{~cm} \mathrm{~s}^{-1}$. Transfer line temperature was $295^{\circ} \mathrm{C}$.

Mass spectrometry. Tune setting: Ion source temperature of $200^{\circ} \mathrm{C}$ : electron multiplier at $1050-1175 \mathrm{~V}$ (Auto tuned to a gain of $\left.3-4 \times 10^{5}\right)$, filament emission current $250 \mathrm{~mA}$ at 70 $\mathrm{eV}$ : high mass adjustment $50 \%$, and automatic gain control 50 (arbitrary unit. range 1-300). For MS/MS the parent ion was selected $m z \pm 0.5$. CID voltage was set from 0.3 to 5.0 $V$ and the $q$ value was set at $0.225,0.30$, and 0.45 . Comparing with the MS/MS spectrum. the full scan spectrum of belzo(a)pyrene was acquired from $m z 100$ to 285 at a scan time of $0.36 \mathrm{sec}$.

Quantitation of samples. The standard curve was obtained by using 20,50, 100.500, $1000 \mathrm{ng} \mathrm{mL}^{-1}$ benzo(a)pyrene. All quantitation was performed by internal standardization using pery leme- $\mathrm{d}_{12}$ at the $200 \mathrm{ng} \mathrm{mL} \mathrm{m}^{-1}$ level as the internal standard. CID condition used for quantitation is shown in Table 1, and the quantitation ion for GC-El/MS was the molecular ion $\left(\mathrm{M}^{\prime}\right) .252$.

\section{Results and Discussion}

There are a number of approaches to achieve maximum sensitivity and low interference in MS/MS analysis of ion trap mass spectrometry: The observed limit of detection in MS/MS depends on a number of factors. including intensity of the precursor ion CID efficiency, fragmentation efficiency and collection efficiency. ${ }^{-}$Anong these, the q value and $\mathrm{CLD}$ voltage are critical parameters in ion trap MS/MS operation.

Ion abundance versus excitation energy. The excitation energy is controlled by the resonance excitation RF voltage applied to the endcap electrodes of the ion trap mass analyzer in $\mathrm{MS}^{\text {n }}$ to cause the production of product ions from precursor ions through $\mathrm{CD}$. When resonance excitation RF voltage is applied, it enhances the motion of selected ions in the axial direction to impart kinetic energy to them. thereby exciting them. When they are excited. collisions with the helium damping gas in the ion trap become more energetic until the ions gain enough internal energy to cause them to dissociate into product ions.' ?

Figure 2 shows the ion abundance curves for the benzo(a)py rene at different resonance excitation energ: The precursor ion was the highest abundant ion in the mass spectnum when the excitation voltage was less than $1.5 \mathrm{~V}$. For excitation voltages above $1.5 \mathrm{~V}$, the precursor ion was fragmented to the product ion such as $m z 250$ and 248 . were formed from the precursor ion in a processes of sequential hydrogen loss. "When the excitation voltage was

Table 1. C.IL resonant condition for yuantitation

\begin{tabular}{|c|c|c|c|c|c|c|}
\hline Compounds & $\begin{array}{l}\text { Segment time } \\
(\text { min })\end{array}$ & CID ion & $\begin{array}{c}\text { lixeitation energy } \\
\text { applied (V) }\end{array}$ & $\begin{array}{l}\text { Maximutrn excitation } \\
\text { energy (q value) }\end{array}$ & $\begin{array}{c}\text { Isolation time } \\
\text { (tr1s) }\end{array}$ & $\begin{array}{l}\text { Ficitalion time } \\
\text { (ms) }\end{array}$ \\
\hline $\begin{array}{l}\text { Benfo(a)prete } \\
\text { Perylene-d } d_{12}\end{array}$ & $32-38$ & $\begin{array}{l}252 \\
264\end{array}$ & 1.5 & 0.45 & 8 & 15 \\
\hline
\end{tabular}




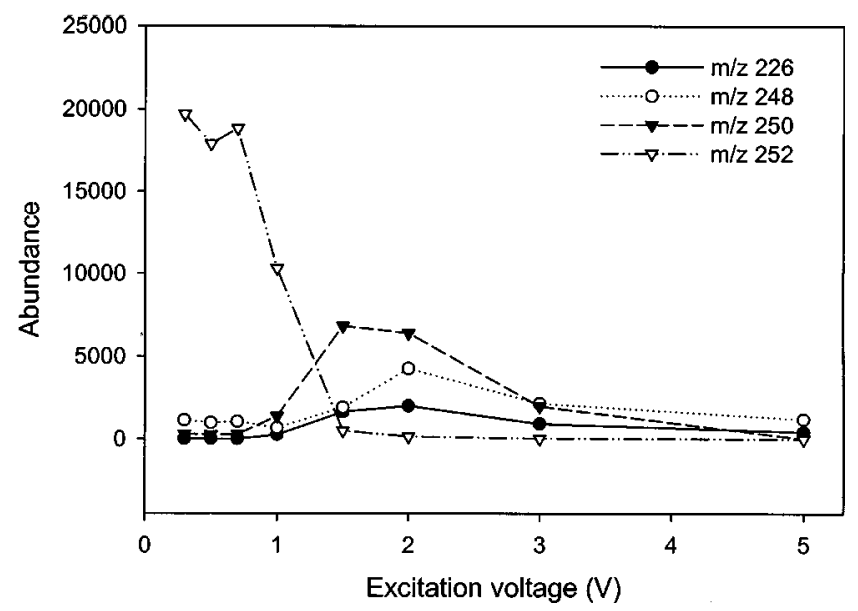

Figure 2. lon abundance versus excitation vollage curves at a value, 0.45 .

less than $1.5 \mathrm{~V}$, the fragmentation pattem was similar to that of El full scan spectnum with slightly lower intensity of the primary ion. And when the excitation voltage was more than $2.0 \mathrm{~V}$, the overall ion intensity was severely reduced. As a result we concluded that the most adequate condition of the excitation voltage was $1.5 \mathrm{~V}$ for the lowest detection limit and the sufficient conformation ion intensity:

Ion abundance versus q value. In the PolarisQ ion trap mass spectrometer, the q value. a parameter of the Mathieu equation. ${ }^{18}$ can be set at $0.225,0.30$. or 0.45 . These values refer to the main RF voltage that is used during mass analyzer CID of the precursor ion and adduct formation. This parameter defines the amount of energy holding the precursor ion in the trap during excitation. and which. as a result. affects the usable mass range. If the q value is too low, energetic precursors and/or product ions are lost from ion trap. Conversely. the higher q value limits the lower the mass limit that can be acquired. ${ }^{12.2 ? 1}$

Figure 3 shows the ion abundance of several excitation voltages for different q values. When the RF excitation voltage was lower than $1.0 \mathrm{~V}$, the q values did not affect the ion fragmentation and the intensity of the produced ion (Figure $3 \mathrm{a}, 3 \mathrm{~b} .3 \mathrm{c}$ ). When the q value was 0.45 and the excitation RF voltage was more then $1.5 \mathrm{~V}$. an adequate spectrum was acquired for quantitation and conformation. For benzo(a)py rene analysis by MS/MS the adequate $\mathrm{q}$ value was 0.45 . hence the rest of the experiment was performed at this value.

To determine the average abundance of the ions in the belzo(a)pyrene CID spectrum. the compounds were run three times and the average abundance of each ion was determined. The spectra ty pically exhibited good reproducibility except that the excitation $R F$ voltage was $2.0 \mathrm{~V}$ (Table 2).

Limit of Detection (LOD). The limit of detection defined as three times the signal-to-noise $(\mathrm{S} / \mathrm{N})$ ratio. ${ }^{\text {?i..21 }}$ for the beizo(a)pyrene is shown in Table 3. The LODs of benzo (a)py rene were 3.18 and $0.85 \mathrm{ng} \mathrm{mL} \mathrm{m}^{-1}$ for $\mathrm{El}$ and $\mathrm{CID}$ full scan mode. respectively. The excitation voltage applied to the end cap electrodes was the most important factor in deciding the LODs. At lower excitation voltages. the precursor ion was rarely fragmented and the pattern was similar to those of El full scan spectra (Figure $4 \mathrm{a}$ and $+\mathrm{b}$ ). This is caused by the stable nature of the precursor ion: therefore, the higher CID energy was required to form a single intense product ion with the conformation ion. $\mathrm{mz}$ 226 . When the excitation voltage exceeded $1.5 \mathrm{~V}$, several ions with similar intensity occurred, such as $m=250,249$ and 2+8. by sequential hydrogen loss. The ion abundance of the primary ion was significantly downed from about 7,000 at the excitation voltage of $1.5 \mathrm{~V}$ to about 2.000 at the excitation voltage of $3.0 \mathrm{~V}$. As a result, the LOD increased slightly from $0.85 \mathrm{ng} \mathrm{mL}^{-1}$ at the excitation voltage of $1.5 \mathrm{~V}$ to $1.39 \mathrm{ng} \mathrm{mL^{-1 }}$ at the excitation voltage of $3.0 \mathrm{~V}$.

Table 2. Relative abundance and short-term precision ol major (CID) ions

\begin{tabular}{|c|c|c|c|c|c|c|c|c|c|}
\hline \multirow{2}{*}{$\begin{array}{c}\text { Excitation } \\
\text { voltage }\end{array}$} & \multirow[b]{2}{*}{ q falue } & \multicolumn{2}{|c|}{$m \geq 252$} & \multicolumn{2}{|c|}{$m z 250$} & \multicolumn{2}{|c|}{$m z 248$} & \multicolumn{2}{|c|}{$m z 226$} \\
\hline & & avcrage" & $\begin{array}{c}1 \sigma \\
\left({ }^{0} 0\right)^{b}\end{array}$ & avcrage & $\begin{array}{c}1 \sigma \\
(00)\end{array}$ & average & $\begin{array}{l}1 \sigma \\
(0)\end{array}$ & average & $\begin{array}{c}1 \sigma \\
\left(\begin{array}{ll}n_{0} \\
0\end{array}\right)\end{array}$ \\
\hline \multirow[t]{3}{*}{$2.0 \mathrm{~V}$} & 0.225 & 6.5 & 2.2 & () & (b) & 75.8 & 30.1 & 1.3 & 1.88 \\
\hline & $(0 . .30)$ & It) & - & 84 & 15.6 & $51 . .3$ & 4.1 & $20 . .3$ & 2.99 \\
\hline & 0.45 & 2.4 & 11.8 & $I(H)$ & - & 67.2 & 6.1 & .34 .1 & 2.1 .3 \\
\hline \multirow[t]{3}{*}{$1.0 \mathrm{~V}$} & 0.225 & 100 & - & .34 .2 & 2.1 & 12.5 & 1.4 & 0.0 .3 & 0.04 \\
\hline & (0).30) & $I 00$ & - & 290 & 2.4 & 6.4 & 1.2 & 2.8 & (). 12 \\
\hline & 0.45 & 100 & - & 20.8 & 2.9 & 6.6 & 0.4 & 2.5 & 0.15 \\
\hline \multirow[t]{3}{*}{$0.7 \mathrm{~V}$} & 0.225 & 100 & - & .36 .5 & 2.1 & $5 . . ?$ & 0.4 & 0.012 & 0.013 \\
\hline & (1)..30) & $\mathrm{I}(1) 0$ & - & .36 .2 & $1 . .3$ & 5.7 & 0.2 & 0.06 & 0.015 \\
\hline & 0.45 & 100 & - & 16.1 & 0.4 & 5.6 & 0.4 & 0.02 & 0.04 \\
\hline \multirow[t]{3}{*}{$0.5 \mathrm{~V}$} & 0.225 & 100 & - & 48.1 & 3.3 & 5.9 & 1.1 & 0.012 & 0.013 \\
\hline & 0.30 & 100 & - & .34 .7 & 1.4 & 5.6 & 0.2 & 0.04 & 0.012 \\
\hline & 0.45 & $I 00$ & - & 10.3 & 0.6 & 5.5 & 0.8 & 0.04 & 0.012 \\
\hline \multirow[t]{3}{*}{$0.3 \mathrm{~V}$} & 0.225 & 100 & - & .38 .0 & 0.6 & 5.6 & 0.2 & 0.012 & 0.013 \\
\hline & 0.30 & $I 00$ & - & .35 .9 & 1.8 & 4.9 & 0.7 & 0.014 & 0.07 \\
\hline & 0.45 & 100 & - & 15.2 & 0.8 & 5.8 & 0.1 & 0.06 & 0.06 \\
\hline
\end{tabular}

"Average: abundance relative to base peak based on three injeclions. "Standard devialicn based on three replicalions. 

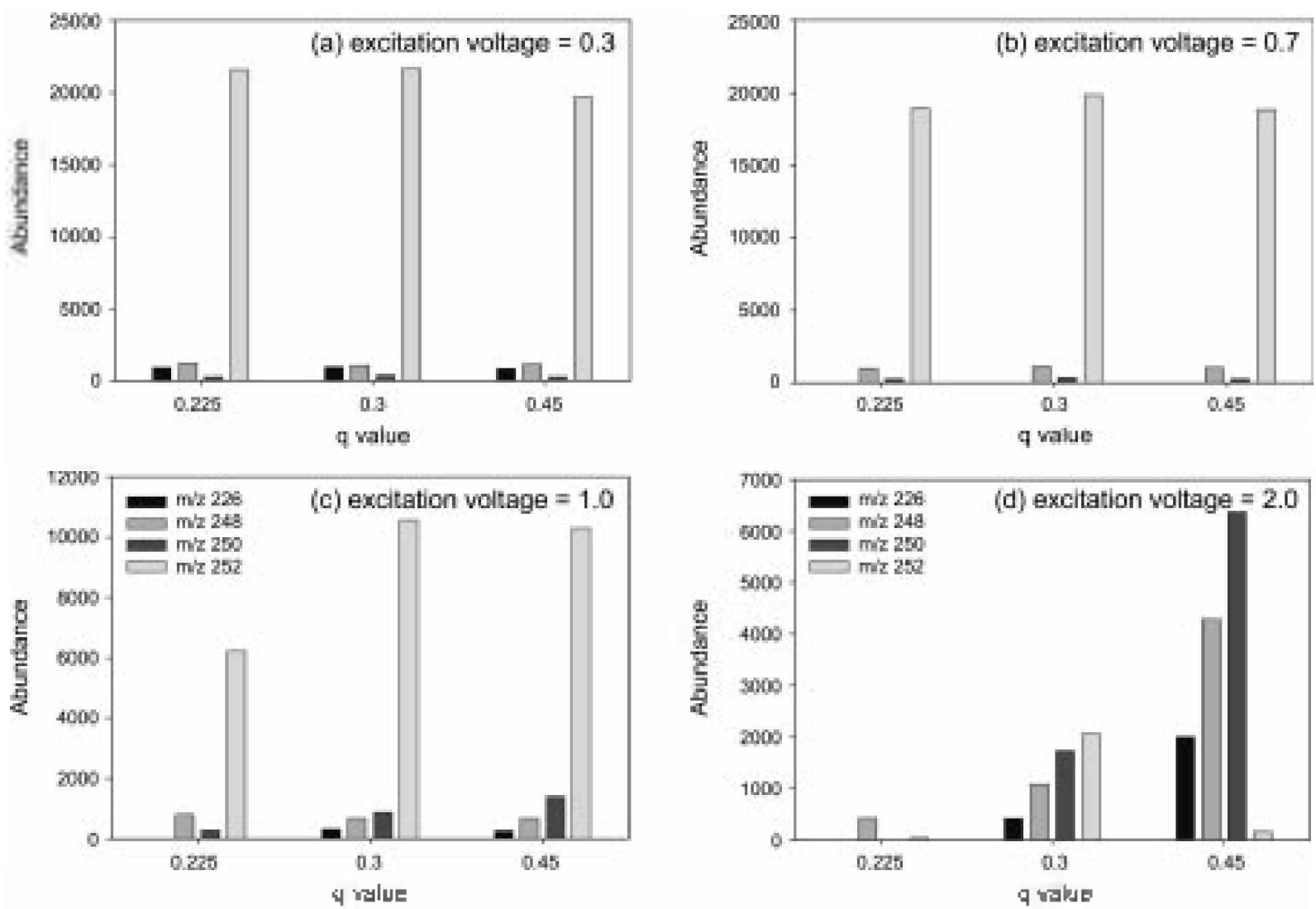

Figure 3. Ion abundance versus of value for benzo(a)py rene at the excitation voltage al 0.3 (a), 0.7 (b), 1.0 (c), 2.0 (d).

Table 3. Limil of detection (LOD) of Lil and (CIL) (ng $\left.\mathrm{mL}^{-1}\right)$

\begin{tabular}{ccccccc}
\hline \multirow{2}{*}{ Compound } & \multirow{2}{*}{$\mathrm{EI}^{\alpha}$} & \multicolumn{5}{c}{ C.II $^{b}$ - excilation energy (V) } \\
\cline { 3 - 7 } & & $0.3(252)^{r}$ & $0.7(252)$ & $1.5(250)$ & $3.0(250)$ & $5.0(248)$ \\
\hline Benzo(a)pyrenc & 3.18 & 3.63 & 4.46 & 0.85 & 1.39 & 1.71 \\
\hline
\end{tabular}

"Extracted ion chromatogram of molecular ion $\left(\mathrm{M}^{+}\right)$was used lor quantitation. " $\mathrm{q}$ value was set at 0.45 . 'Number in parenthesis are the quantitation mass.

Mass spectrum. The full scan spectra and the MS/MS spectrum of benzo(a)py rene are shown in Figure 4 . In the EI full scan spectra. the primary ion is the molecular ion. and it is similarly located $m z 126$, and 113. such as the conventional quadrupole mass spectrum from NIST librar: When the excitation voltage was more than $1.5 \mathrm{~V}, m z 226$ as a product ion can also be clearly identified. This ion could be used as a conformation ion for the complex matrix samples.

Soil analysis. A soil sample was analyzed to determine the applicability of CID analysis to real samples. According to the EPA methods. the sample was extracted. cleaned. ${ }^{9}$ and then injected into the ion trap GC-MS. The EI and CID response curves for the benzo(a)py rene were linear and the correlation coefficients of both were more than 0.99 .

Figure 5 shows the full scan chromatogram of EI of a soil sample without cleaning. In total ion chromatogram (Figure 5a) of soil without cleaning the $\mathrm{S} / \mathrm{N}$ ratio was 1 , and it was not easy to identify the peak of benzo(a)pyrene. But the $S / N$ ratio of extracted ion chromatogram of $m z 252$ (Figure $5 \mathrm{~b}$ ) was 30. In MS/MS analysis, the $\mathrm{S} / \mathrm{N}$ matios of benzo(a)pyrene were 26 and 63 for total ion chromatogram (Figure 6a) and extracted ion chromatogram of $m z 250$ (Figure $6 \mathrm{~b}$ ), respectively. The $\mathrm{S} / \mathrm{N}$ ratio of $\mathrm{CID}$ was about 2 times stronger than that of EI analysis in extracted ion chromatogram. Though LOD of MS/MS analysis was about 10 times lower than that of EI analysis, both analysis methods in real sample gave sufficient quantitation power. Note that total ion chromatogram of GC-MS/MS is much simpler than that of the GC-EI/MS, that is because only the progeny ion of the precursor ion for the target analyte was scanned. Also. the MS/MS analysis allows for the extra qualitative conformation of the isomers based on the product ion abundance. We were able to find an exact matching of ion abundance ratio of $\mathrm{mz} 250$ and 226 between the spectrum of benzo(a)pyrene standard and soil extractant. When more complex samples. such as used motor oil. sewage sludge, and plants are encountered, the MS/MS analy sis will be the altemative way not only to decrease the detection limit but also to enhance the confirmative 

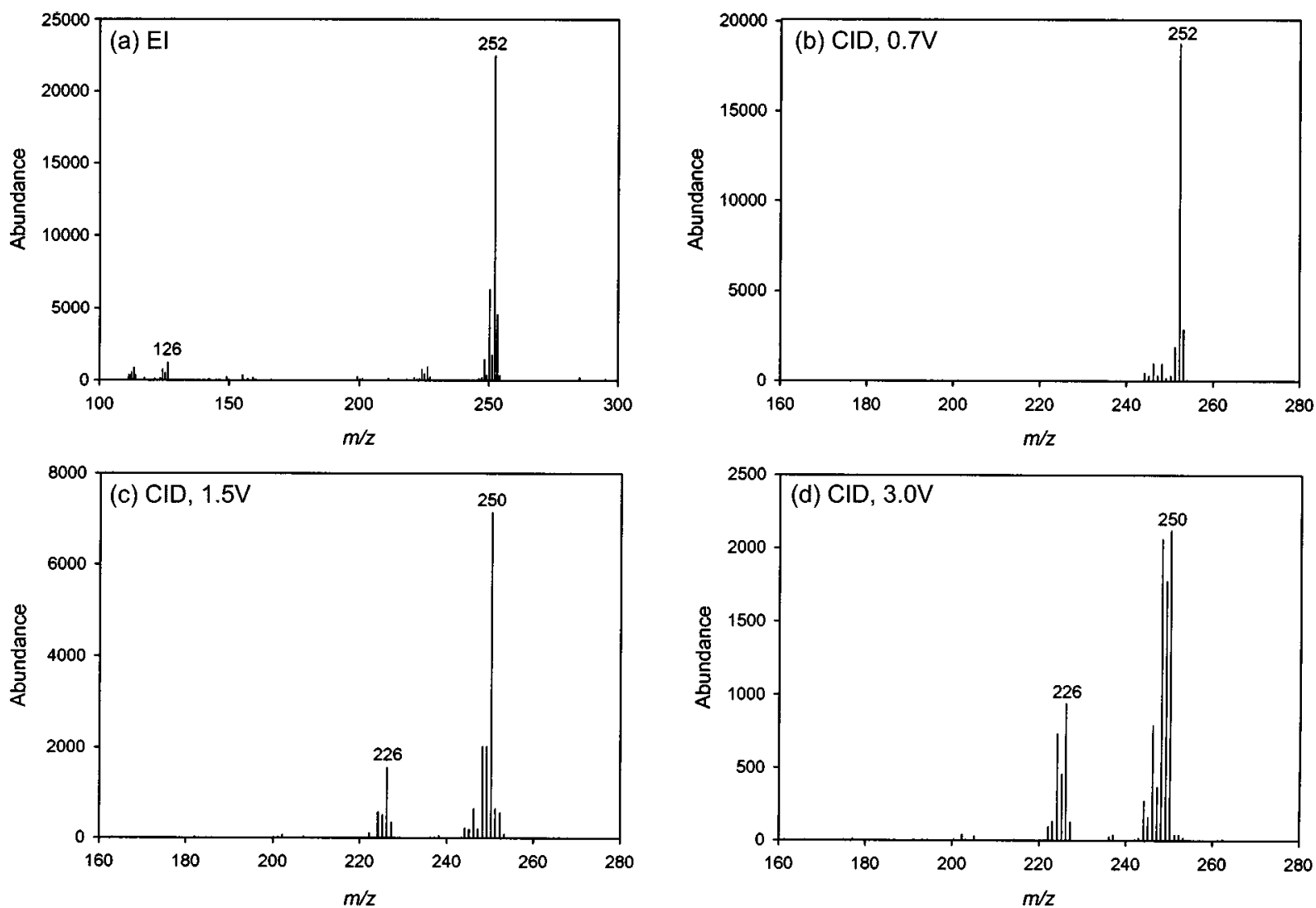

Figure 4. Spectra of LI (a) and (CIL) spectra at the excilation wolage 0.7 (b), 1.5 (c), 3.0 (d) of benzor a py rene.
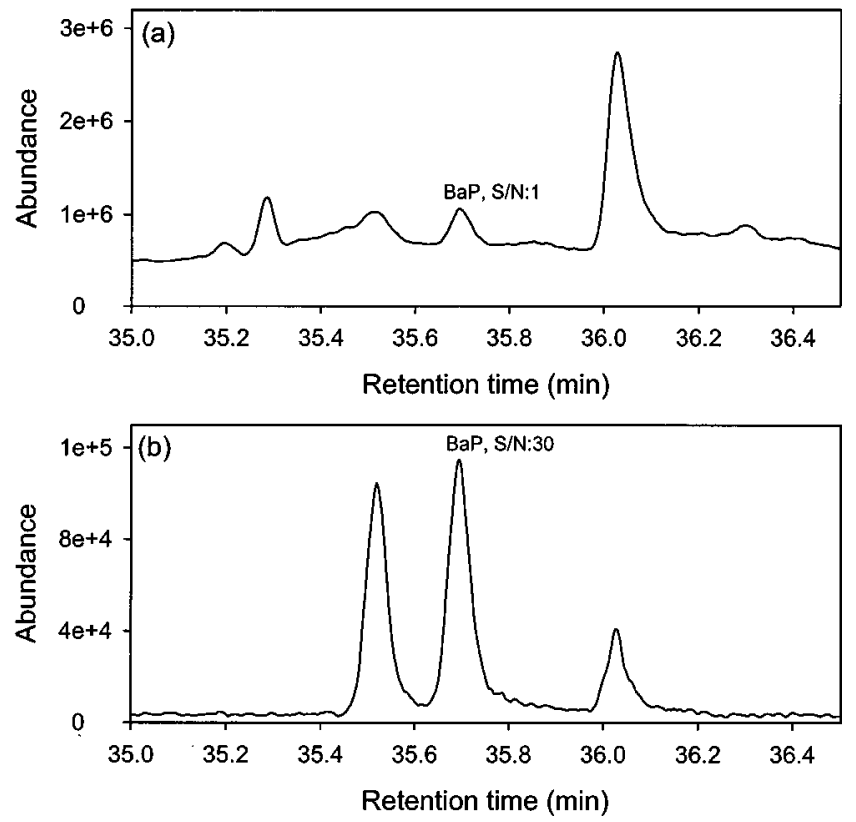

Figure 5. F. chromatogtam of a soil sample: total ion chromatogram (a) and extracted ion chromatogramss at $m$ z 252 (b)

capability and reduce the background noise.

The quantitative result of EI and MS/MS analysis are shown in Table 4. The concentration of benzo(a)pyrene quantitated by EI and MS/MS analysis was 168 and $162 \mu \mathrm{g}$ $\mathrm{kg}^{-1}$. respectively (Table 4 ). Also shown in the table are the
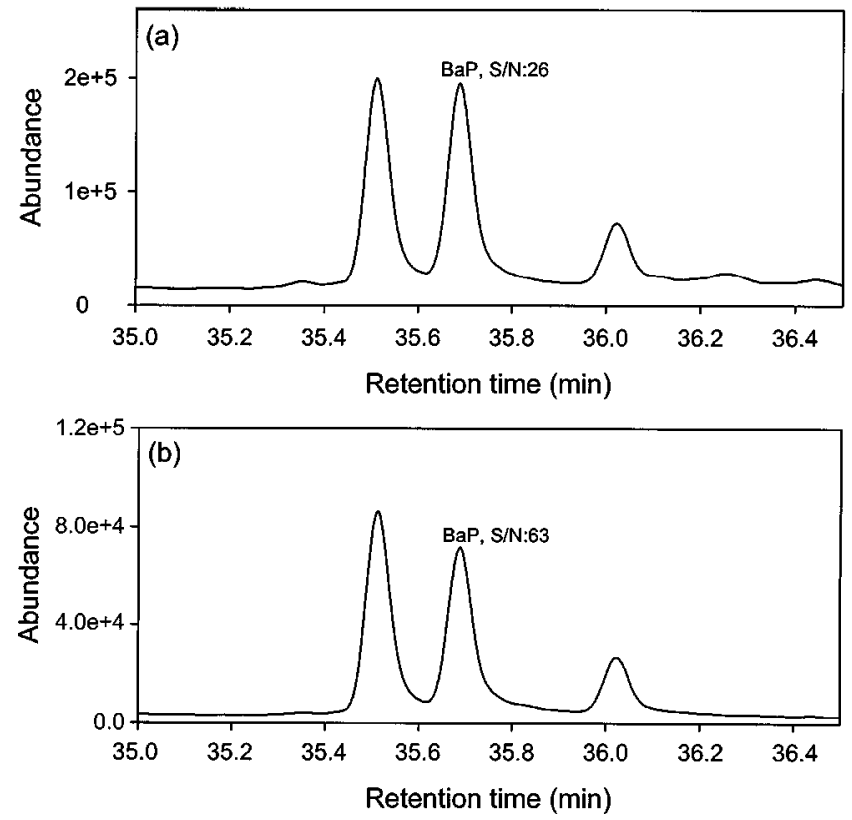

Figure 6. CID chromatogram of a soil sample: total ion cliromatogram (a) and extracted ion chromatograms at $m$ z 250 (b)

standard deviation of each analysis and the $\mathrm{S} / \mathrm{N}$ ratio of soil samples with and without cleaning. Comparing the GC-EI/ MS analysis. repeatability and sensitivity were slightly improved by the GC-MS/MS analysis in a real soil sample (Table 4). 
Table 4. Mnalysis and quality parameter of benzota)pyrene in a soil xample

\begin{tabular}{|c|c|c|c|c|}
\hline \multirow[b]{2}{*}{ Quantitations } & \multirow{2}{*}{$\begin{array}{l}\text { Concentration } \\
\left(\mu \mathrm{g} \mathrm{kg}{ }^{3}\right)\end{array}$} & \multirow{2}{*}{$\begin{array}{l}1 \sigma \\
\left(0_{0}\right)^{b}\end{array}$} & \multicolumn{2}{|c|}{$S N$ ratio ${ }^{c}$} \\
\hline & & & $\begin{array}{c}\text { with } \\
\text { cleanup }\end{array}$ & $\begin{array}{l}\text { uithout } \\
\text { cleanup }\end{array}$ \\
\hline EI (tull scan) ${ }^{\sigma}$ & 168 & 6.1 & 83 & 30 \\
\hline $\mathrm{CID}^{b}(\mathrm{MS} \mathrm{MS})$ & 162 & 4.1 & 119 & 63 \\
\hline
\end{tabular}

"Extracted ion chromatogram of molecular ion (M') was used for quantitation. "Standard deviation, based on three injections. "q value and quantitation mass was 0.45 and $m=250$, respectivej:

\section{Conclusion}

The data obtained in this study demonstrate the usefulness of ion trap GC-MS/MS experiments for detecting and quantifying trace amounts of bellzo(a)py rene. The primary objective of this study is to improve the limit of detection of analysis of benzo(a)pyrene in soil samples. Although it is unreasonable to directly compare the CID conditions and LODs with that of other research results. the LODs were similar to previous research results, and we could find that the stability of relative ion abundance and ion intensity in MS/MS experiments was noticeably improved and. as a result, we were able to more precisely quantify the concentration of PAHs. compared with El. in a soil sample. Tecluniques to detect trace levels of contaminants in complex matrices. such as the one outlined in this work. are important tools in analyzing environmental samples.

\section{References}

1. Greenburg. A.: Hsu. C.: Rolhman. N.: Strickland. 1. T. Potyctedic Aromatic Compenonds 1993. 3. 101.

2. Warzecla. L. J. High Resol. Chromatogr 1996. 19. 639.

3. Pyle, S. M.; Betowski, I.. D.: Mareus, A. B.: Winnik, W.: Brittain.
R. D.J.Am. Soc Hass Spectrom. 1997. S. 183.

4. Nondek. L.: Kuzileh. M.: Krupieka. S. Chromatophia 1993. 37. 381 .

5. Agency for Toxic Subtances and Disease Registry. ATSDR: Atlanta, GA. 1995: p 458 .

6. National Library of Medicine. Ilazardous Substance Data Bank (HSDB, CD-ROH Database: Micromedes Inc.: Denver. CO.. 1988.

7. Suess. M. T. The Sciknce of the Toul Emwommen 1976. 6. 239.

8. 7amperlini. G. C. M.: Silva, M. R.: Vilegas, W. (h/omatographia 1997, +6.655

9. U. S. Fonvirmmental Protection A gency Test . Hethods for Fuahtuting Solid llaste Ptrosical Chemical methods. Sil-846. EPA. Olice of Solid Waste and Emergency Response: Washington. D.C.. 1997.

10. U. S. Tnvirommental Protection Ageney Analytical Methods for Regulated Drinking Water C'ontaninations, Find Rule: FPA. Office of Ground Water and Drinking Water: Washington, D.C., 1994.

11. Sater. T.: Boelum. P. The Ciste of Defensible Andtoticat Chemical Measmements for Oil Spill Nattral Resoure Damerge Assessment. Proceedings of Oil Spill Conference, 1991: pp 36.3-369.

12. Quarmby, S.: Guckenberger, B. C'ontent of the Help File ith Noaliby 1.2; Johtss. K., Fd.: Technical Publications: Austin. TX. 2001

13. Wang. M.: Schachterle. S.: Well. G. J. Am. Soc Mass Spectrom. 1996. 7. 668 .

14. Abraham, V. M.: I.xtnt. Ir.. B. C. J. of Chromatography al 1997. 790.131

15. Ding. W. II.: T7ing. S. H. J. of Clwomatography i 1998. 824 . 79.

16. Mosi. A. A.: Reimer. K. I.: Eigendorl. (j. K. Talama 1997. 4t. 985.

17. Thomson, B. A.: Douglas, D. J.: IJager, J. W.: Jolliffe. C. I... inal. Chem 1995. 67. 1696.

18. Jonscher, K. R.; Yates, III. I. R. Anahtical Biochemistm 1997. 24. 1 .

19. Bowers. L. D.: Borts. D. I. Jommal of Chromatography $B 1996$. 687.69

20. Knoll, J. F.. J. of (Wwomatographic Science 1985, 23, 422.

21. I.ong. G. I..: Winctordner, J. D. Inalyfical Chemistry 1983, 55 , $71.3 \wedge$ 